\title{
Comments on "Role of Anions (Tetrafluoroborate, Perchlorate) of Tetrabutylammonium Salts in Determining Solvation Effects Prevailing in Industrially Essential Solvents Probed by Conductance and FT-IR Spectra"
}

\author{
William E. Acree, Jr.
}

Department of Chemistry, University of North Texas, 1155 Union Circle Drive \#305070, Denton, Texas 76203-5017 United States

ABSTRACT: Several computational and graphical errors in the paper are pointed out, as well as errors in mathematical equations. The calculation of ionic limiting molar conductances is discussed based on the tetrabutylammonium tetraphenylboride reference electrolyte method.

Tn a recent paper published in the Journal of Chemical \& Engineering Data (JCED) Banik and Roy ${ }^{1}$ analyzed molecular interactions between tetrabutylammonium perchlorate $\left[\mathrm{Bu}_{4} \mathrm{NClO}_{4}\right]$ and tetrabutyammonium tetrafluoroborate $\left[\mathrm{Bu}_{4} \mathrm{NBF}_{4}\right]$ ion salts and nitromethane, methylformamide, and formamide using experimental conductance data and FT-IR spectra. The authors reported the limiting molar conductances $\left(\Lambda_{0}\right)$ of the dissolved ionic salts, the overall pairing association constant $\left(K_{\mathrm{A}}\right)$ of the ionic salt, and the ionic limiting molar conductances $\left(\lambda_{0}^{ \pm}\right)$of the $\mathrm{Bu}_{4} \mathrm{~N}^{+}$cation and $\mathrm{ClO}_{4}^{-}$and $\mathrm{BF}_{4}^{-}$ anions in the three solvents studied. While many aspects of the study appear to be correct, there are several shortcomings in the published paper of which readers need to be aware.

First, all six of the $\Delta G^{\circ}$ values given in Table 3 of the paper are wrong. If one substitutes the authors' numerical values of $K_{\mathrm{A}}$ into eq 13 of the manuscript (renumbered below as eq 1 )

$$
\begin{aligned}
& \Delta G^{\mathrm{o}}=-R T \ln K_{\mathrm{A}} \\
& \begin{aligned}
\Delta G^{\mathrm{o}} /\left(\mathrm{kJ} \mathrm{mol}^{-1}\right) & =-(0.008314)(298.15) \ln 183.09 \\
& =-12.914
\end{aligned}
\end{aligned}
$$

which differs from the authors' value by a factor of 10 . The value that is given in Table 1 corresponding to $K_{\mathrm{A}}=183.09$ is $\Delta G^{\circ} /\left(\mathrm{kJ} \mathrm{mol}^{-1}\right)=-1.29$. The miscalculation also makes the graphed values in Figure 4 wrong. The right-hand axis labeling for the graph should range from $\Delta G^{\circ} /\left(\mathrm{kJ} \mathrm{mol}^{-1}\right)=-10$ to $\Delta G^{\mathrm{o}} /\left(\mathrm{kJ} \mathrm{mol}^{-1}\right)=-16$.

Second, the data points in Figure 2 have been incorrectly graphed. The authors have graphed limiting molar conductances of the two ionic salts, $\Lambda_{0} \cdot 10^{4} /\left(\mathrm{S} \mathrm{m}^{2} \mathrm{~mol}^{-1}\right)$ values, according to the labeling on the left-hand side axis, and have graphed the Walden product of the two ionic salts, $\Lambda_{0} \eta \cdot 10^{4} /(\mathrm{S}$ $\mathrm{m}^{2} \mathrm{~mol}^{-1} \mathrm{mPa} \mathrm{s}$ ) values, according to the labeling on the righthand side axis for each. The text directly above Figure 2 indicates that the values are given in Table 3. Unfortunately, the graphed values do not correspond with the data given in Table 3. The solid triangle according to the figure caption is the limiting molar conductance for $\mathrm{Bu}_{4} \mathrm{NBF}_{4}$, and the graphed value for nitromethane (solvent designated $\mathrm{NM}$ ) is somewhere between 150 and 170. The numerical values for $\mathrm{Bu}_{4} \mathrm{NBF}_{4}$ given in Table 3 for $\Lambda_{0} \cdot 10^{4} /\left(\mathrm{S} \mathrm{m}^{2} \mathrm{~mol}^{-1}\right)$ range between values of 26.18 and 94.60. A value of $\Lambda_{0} \cdot 10^{4} /\left(\mathrm{S} \mathrm{m}^{2} \mathrm{~mol}^{-1}\right)>150$ is not in the Table. There are similar problems with other graphed values in Table 3. For example, the labeling on the right-hand axis goes between $\Lambda_{0} \eta \cdot 10^{4}\left(\mathrm{~S} \mathrm{~m}^{2} \mathrm{~mol}^{-1} \mathrm{mPa} \mathrm{s}\right)=35$ and $\Lambda_{0} \eta$. $10^{4}\left(\mathrm{~S} \mathrm{~m}^{2} \mathrm{~mol}^{-1} \mathrm{mPa} \mathrm{s}\right)=95$, yet the last value in the sixth column of Table 3 is $\Lambda_{0} \eta \cdot 10^{4}\left(\mathrm{~S} \mathrm{~m}^{2} \mathrm{~mol}^{-1} \mathrm{mPa} \mathrm{s}\right)=118.6$. This value is not represented in the graph.

Third, eq 7 in the manuscript (renumbered below as eq 2) may be in error.

$$
K_{\mathrm{A}}=K_{\mathrm{R}} /(1-\alpha)=K_{\mathrm{R}} /\left(1+K_{\mathrm{S}}\right)
$$

The manuscript text immediately below eq 7 states that $K_{\mathrm{S}}$ is the association constant of the contact-pairs, $K_{R}$ is the associated constant of the solvent-separated pairs, $K_{\mathrm{A}}$ is the overall pairing constant, and $\alpha$ is the fraction of contact pairs. Let us focus on the last two parts of the equality, namely $K_{\mathrm{R}} /(1$ $-\alpha)=K_{\mathrm{R}} /\left(1+K_{\mathrm{S}}\right)$. Let us divide both sides by $K_{\mathrm{R}}$, and then reciprocate both sides of the equation to get $(1-\alpha)=(1+$ $\left.K_{\mathrm{S}}\right)$. Now subtract 1 from both sides to get, $-\alpha=K_{\mathrm{S}}$. Neither the association constant nor fraction of contact pairs should be negative. The only way to satisfy the mathematical condition of $-\alpha=K_{\mathrm{S}}$ without using a negative value would be for both $\alpha$ and $\mathrm{K}_{\mathrm{S}}$ to equal zero.

Fourth, eq 13a in the published paper that pertains to the calculation of $A$-coefficient is wrong. If one looks at the very last term on the right-hand side of the equation, one sees $\left(\lambda_{+}{ }^{\circ} \lambda_{-}{ }^{\circ} /\right.$ $\left.\Lambda_{0}\right)^{2}$. The equation has appeared numerous times in the published literature $^{2-6}$

$$
A_{\text {theo }}=\frac{0.2577 \Lambda_{0}}{\eta_{0}(\epsilon T)^{0.5} \lambda_{+}^{0} \lambda_{-}^{0}}\left[1-0.6863\left(\frac{\lambda_{+}^{0}-\lambda_{-}^{0}}{\Lambda_{0}}\right)^{2}\right]
$$

and the term in parentheses should contain a negative sign as given by eq 3 above. The negative sign in the equation significantly effects the calculations as one might guess. In the

Received: January 22, 2014

Accepted: March 1, 2014

Published: March 7, 2014 
JCED paper Banik and Roy ${ }^{1}$ state in the first full sentence below eq 13a "Table 3 shows that the A-coefficient is negative and very small, and shows that the existence of the ion-ion interaction is negligible, as compared to the ion-solvent interaction for all of the chosen electrolytes in the studied solvents." With the negative sign in the equation, there is absolutely no way to calculate a negative value for the $A$ coefficient. This makes all six values in the last column of Table 3 wrong. The error in the JCED paper is not a simple typesetting error in that the incorrect equation was used in the authors' calculations.

Fifth, the authors' discussion of how the ionic limiting molar conductances for $\mathrm{Bu}_{4} \mathrm{~N}^{+}$cation, and for $\mathrm{BF}_{4}{ }^{-}$and $\mathrm{ClO}_{4}{ }^{-}$anions is extremely vague and noninformative. On the fifth page of the published paper the authors state "The ionic conductances $\lambda_{\mathrm{o}}{ }^{ \pm}$ for the $\left[\mathrm{Bu}_{4} \mathrm{~N}\right]^{+}$cation and $\mathrm{BF}_{4}{ }^{-}, \mathrm{ClO}_{4}{ }^{-}$anion in different solvent arrangements were computed as described in the literature values (cited reference 19). The ionic limiting molar conductances $\lambda_{\mathrm{o}}{ }^{ \pm}$in investigated solvents were determined by interpolation of the conductance from the literature (cited reference 20) using cubic spline fitting." The cited reference 19 pertains to electrical conductances and viscosities of tetrabutylammonium thiocyanate in acetonitrile where Chakraborty and $\operatorname{Das}^{7}$ estimated the ionic contributions to $\Lambda_{0}$ using the reference electrolyte tetrabutylammonium tetraphenylboride. Cited reference 20 pertains to conductances of tetrabutylammonium tetraphenylboride in propylene carbonate, and in binary mixtures containing carbon tetrachloride and nitrobenzene. Essentially, since the cation and anion were both large and had approximately the same volume, Fuoss and $\mathrm{Hirsch}^{8}$ set the ionic limiting molar conductance of the cation equal to that of the anion. Since the solvents studied by Banik and Roy ${ }^{1}$ are completely different, as well as the electrolytes, it is not apparent how the authors' statement pertaining to references $19^{7}$ and $20^{8}$ is pertinent to their calculations of $\lambda_{0}{ }^{ \pm}$.

If one looks at the ratio $\lambda_{\mathrm{o}}{ }^{ \pm}$(cation) $/ \lambda_{\mathrm{o}}{ }^{ \pm}$(anion) for $\mathrm{Bu}_{4} \mathrm{NBF}_{4}$ the values equal 0.562 for nitromethane, 0.563 for $\mathrm{N}$ methylformamide, and 0.563 for formamide. The ratio of the crystallographic radii of the anion/divided by radii of the cation equals 0.563 . Similarly, one can look at the ratio $\lambda_{\mathrm{o}}{ }^{ \pm}$(cation)/ $\lambda_{\mathrm{o}}^{ \pm}$(anion) for $\mathrm{Bu}_{4} \mathrm{NClO}_{4}$, the values equal 0.486 for nitromethane, 0.486 for $N$-methylformamide, and 0.486 for formamide. Again, the ratio of the crystallographic radii anion/ divided by radii cation equals 0.486 . It appears that the authors have built this requirement into the calculation.

Banik and Roy ${ }^{1}$ imply in the abstract of their paper that the tetrabutylammonium tetraphenylboride reference electrolyte was used to estimate the ionic limiting molar conductances of $\mathrm{Bu}_{4} \mathrm{~N}^{+}, \mathrm{BF}_{4}^{-}$and $\mathrm{ClO}_{4}^{-}$ions. The tetrabutylammonium tetraphenylboride reference electrolyte method assumes that the ionic limiting molar conductance of tetrabutylammonium is equal to (or in some applications nearly equal to) the ionic limiting molar conductance of tetraphenylboride. The tetrabutylammonium and tetraphenylboride ions are large (small charge density), are of comparable size and are expected to undergo very little specific interactions with the solvents. This is not the case for the ions studied by Banik and Roy. I think that the authors may have mistook the approximation that others ${ }^{9-11}$ have used for calculating ionic limiting molar conductances of tetrabutylammonium tetraphenylboride, $\lambda_{\mathrm{o}}{ }^{ \pm}$(cation) $/ \lambda_{\mathrm{o}}{ }^{ \pm}$(anion) $=$crystallographic radii of the anion/ divided by radii of the cation to apply to all ions. That would be an incorrect interpretation of the tetrabutylammonium tetraphenylboride reference electrolyte method.

A more appropriate calculation of the $\lambda_{\mathrm{o}}{ }^{ \pm}$numerical values would be based on the tetrabutylammonium tetraphenylboride reference electrolyte method. The numerical values of $\lambda_{\mathrm{o}}{ }^{ \pm}$for the tetrabuylammonium cation would be set equal to the numerical values of $\lambda_{\mathrm{o}}{ }^{ \pm}$for the tetraphenylboride anion in each of the three solvents studied. This is easy to do in the case of nitromethane as Dewan and Roy ${ }^{12}$ published a value of $\Lambda_{0} \cdot 10^{4} /$ $\left(\mathrm{S} \mathrm{m} \mathrm{mol}^{-1}\right)=66.74$ for tetrabutylammonium tetraphenylboride in nitromethane. This would give a numerical value of $\lambda_{\mathrm{o}}{ }^{ \pm} \cdot 10^{4} /\left(\mathrm{S} \mathrm{m}^{2} \mathrm{~mol}^{-1}\right)=33.37$ for both the tetrabutylammonium and tetraphenylboride ions. One would then be able to calculate $\lambda_{\mathrm{o}}^{ \pm} \cdot 10^{4} /\left(\mathrm{S} \mathrm{m}^{2} \mathrm{~mol}^{-1}\right)$ for the perchlorate ion as $111.42-33.37=78.08$ from the value of $\Lambda_{0} \cdot 10^{4} /\left(\mathrm{S} \mathrm{m}^{2} \mathrm{~mol}^{-1}\right)$ listed in Table 3 , and a value of $\lambda_{\mathrm{o}}^{ \pm} \cdot 10^{4} /\left(\mathrm{S} \mathrm{m}^{2} \mathrm{~mol}^{-1}\right)=94.60$ $-33.37=61.23$ for the tetrafluoroborate anion. The values given by Banik and Roy ${ }^{1}$ were $\lambda_{\mathrm{o}}^{ \pm} \cdot 10^{4} /\left(\mathrm{S} \mathrm{m}^{2} \mathrm{~mol}^{-1}\right)=74.99$ and $\lambda_{\mathrm{o}}^{ \pm} \cdot 10^{4} /\left(\mathrm{S} \mathrm{m}^{2} \mathrm{~mol}^{-1}\right)=60.53$ for the perchlorate and tetrafluoroborate ions, respectively. The method illustrated above is based on the reference electrolyte method proposed by Fuoss and Hirsch. ${ }^{8}$ One could alternatively use another version $^{9,10}$ that takes into account the slight differences in ion size.

There is published conductivity data for tetrabutylammonium tetraphenylboride in $\mathrm{N}$-methylformamide. ${ }^{9}$ One would calculate a numerical value of $\lambda_{\mathrm{o}}^{ \pm} \cdot 10^{4}=13.55$ for the tetrabutylammonium cation from the authors' data. (Tsierkezos and Philippopoulos 9 calculated a slightly different numerical value of $\lambda_{\mathrm{o}}^{ \pm} \cdot 10^{4}=14.09$ as they assumed that the molar conductivity of the tetrabutylammonium was slightly larger than the molar conductivity of the tetraphenylborate anion; that is, $\lambda_{\mathrm{o}}^{ \pm}$cation $=1.07 \cdot \lambda_{\mathrm{o}}{ }^{ \pm}$anion. This particular approach takes into account the slight differences in the crystallographic radii of the two reference ions). One would then be able to calculate $\lambda_{\mathrm{o}}{ }^{ \pm} \cdot 10^{4} /\left(\mathrm{S} \mathrm{m}^{2} \mathrm{~mol}^{-1}\right)$ for the perchlorate ion as 50.55 $-13.55=37.00$ from the value of $\Lambda_{0} \cdot 10^{4} /\left(\mathrm{S} \mathrm{m}^{2} \mathrm{~mol}^{-1}\right)$ listed in Table 3, and a value of $\lambda_{\mathrm{o}}^{ \pm} \cdot 10^{4} /\left(\mathrm{S} \mathrm{m}^{2} \mathrm{~mol}^{-1}\right)=41.04-$ $13.55=27.49$ for the tetrafluoroborate anion. The authors' values were $\lambda_{\mathrm{o}}{ }^{ \pm} \cdot 10^{4} /\left(\mathrm{S} \mathrm{m}^{2} \mathrm{~mol}^{-1}\right)=34.02$ and $\lambda_{\mathrm{o}}{ }^{ \pm} \cdot 10^{4} /\left(\mathrm{S} \mathrm{m}^{2}\right.$ $\left.\mathrm{mol}^{-1}\right)=26.26$ for the perchlorate and tetrafluoroborate ions, respectively. It is noted that the method used here for the computation of the ionic limiting molar conductances of $\mathrm{ClO}_{4}{ }^{-}$ and $\mathrm{BF}_{4}{ }^{-}$is essentially the same as that used by Tsierkezos and Philippopoulos for the $\mathrm{PF}_{6}^{-}$. Conductivity data for tetrabutylammonium tetraphenylboride in formamide was not found in a quick search of the published literature.

My comments should not be taken as a criticism of the authors' work. Rather, I think that it is important to point out some of the shortcomings in the published JCED paper to avoid incorrect equations (such as eq 13a) being propagated in the literature, and to point out what I think is a more appropriate method for calculating ionic limiting molar conductances based on the tetrabutylammonium tetraphenylboride reference electrolyte approach.

\section{AUTHOR INFORMATION}

\section{Notes}

The authors declare no competing financial interest.

\section{REFERENCES}

(1) Banik, I.; Roy, M. N. Role of anions (tetrafluoroborate, perchlorate) of tetrabutylammonium salts in determining solvation 
effects prevailing in industrially essential solvents probed by conductance and FT-IR spectra. J. Chem. Eng. Data 2013, 58, $3378-3386$.

(2) Falkenhagen, H.; Vernon, E. L. The viscosity of strong electrolyte solutions according to electrostatic theory. Philos. Mag. 1932, 14, 537565.

(3) Gill, D. S.; Kumari, A.; Gupta, R.; Rana, D.; Puri, J. K.; Jauhar, S. P. Preferential solvation of some copper (I), silver (I) and sodium (I) salts in acetonitrile $+n$-butyronitrile and acetonitrile $+N, N$ dimethylacetamide mixtures. J. Mol. Liq. 2007, 133, 7-10.

(4) Klofutar, C.; Horvat, J.; Bester-Rogac, M.; Rudan-Tasic, D. Viscosity of aqueous solutions of tetramethyl-, tetraethyl-, tetra- $n$ propyl-, tetra- $n$-butyl-, and tetra- $n$-pentylammonium cyclohexylsufamates from 293.15 to $323.15 \mathrm{~K}$. Acta Chim. Slov. 2009, 56, 188-195.

(5) Hammadi, A. Electrical conductance, density, and viscosity in mixtures of alkali-metal halides and glycerol. Int. J. Thermophys. 2004, $25,89-111$.

(6) Svorstol, I.; Sigvartsen, T.; Songstad, J. Solvent properties of dichloromethane, VII. Viscosity studies of electrolytes in dichloromethane. Acta Chem. Scand. B 1988, 42, 133-144.

(7) Chakraborty, J. M.; Das, B. Electrical conductances and viscosities of tetrabutylammonium thiocyanate in acetonitrile in the temperature range $25-45{ }^{\circ} \mathrm{C}$. Z. Phys. Chem. 2004, 218, 219-230.

(8) Fuoss, R. M.; Hirsch, E. Single ion conductances in non-aqueous solvents. J. Am. Chem. Soc. 1960, 82, 1013-1017.

(9) Tsierkezos, N. G.; Philippopoulos, A. I. Studies of ion solvation and ion association of $n$-tetrabutylammonium hexafluorophosphate and $n$-tetrabutylammonium tetraphenylborate in various solvents. Fluid Phase Equilib. 2009, 277, 20-28.

(10) Das, D.; Das, B.; Hazra, D. K. Conductance of some 1:1 electrolytes in $N, N$-dimethylacetamide at $25{ }^{\circ} \mathrm{C}$. J. Solution Chem. 2002, 31, 425-431.

(11) Das, B.; Hazra, D. K. Conductance of selected alkali metal salts in aqueous binary mixtures of 2-methoxyethanol at $25{ }^{\circ} \mathrm{C}$. J. Solution Chem. 1998, 27, 1021-1031.

(12) Dewan, R.; Roy, M. N. Physico-chemical studies of sodium tetraphenylborate and tetrabutylammonium tetraphenylborate in pure nitrobenzene and nitromethane and their binaries probed by conductometry, refractometry and FT-IR spectroscopy. J. Chem. Thermodyn. 2012, 54, 28-34. 